\title{
Desafios e perspectivas da Educação Popular em Saúde na constituição da práxis do Agente Comunitário de Saúde
}

Vera Joana Bornstein ${ }^{(a)}$

Cristina Massadar Morel ${ }^{(b)}$

Ingrid D'avilla Freire Pereira ${ }^{(c)}$

Marcia Raposo Lopes ${ }^{(d)}$

Bornstein VJ, Morel CM, Pereira IDF, Lopes MR. Challenges and prospects of Health Popular Education in its contribution to the praxis of Community Health Agents. Interface (Botucatu). 2014; 18 Supl 2:1327-1340.

This paper discusses Community Health Agent (CHA) work in Brazil, regarding in particular their practice as educators in the context of the national health policy. Authors' experience in the technical course developed for these workers by Escola Politécnica de Saúde Joaquim Venâncio/ Fiocruz and a bibliographical review were the basis for this paper. Results indicate possible contradictions between the legal requirements for the Community Health Agent work and the actual possibility of these agents becoming popular educators. Finally, this paper presents the challenges and prospects health popular education faces if it is to contribute changes in the work process of $\mathrm{CHAs}$ which will lead to effective critical education and popular participation, in order to pave the way for an integral health perspective and a dialogical approach with popular knowledge in the context of primary care.

Keywords: Community Health Agent. Popular health education. Health education.
O estudo problematiza as práticas do Agente Comunitário de Saúde no Brasil, especialmente no que se refere ao seu exercício como educador no contexto das políticas de saúde e de sua atuação profissional. Para a sua construção, considerou-se a experiência das autoras na formação técnica de Agentes Comunitários de Saúde na EPSJV/Fiocruz e a realização de revisão de literatura sobre o tema. Os resultados encontrados indicam possíveis contradições entre as prescrições legais do trabalho do ACS, as expectativas dos serviços em relação à ação desse trabalhador e a possibilidade de ele se constituir como um educador popular. Por fim, apresenta perspectivas e desafios da Educação Popular em Saúde para as mudanças necessárias e possíveis nas práticas dos ACSs, em direção à efetivação da integralidade, da participação popular e do diálogo com o saber popular no âmbito da Atenção Básica.

Palavras-chave: Agente Comunitário de Saúde. Educação Popular em Saúde. Educação em Saúde. $(a, b, c, d)$ Laborat, Escola Politécnica de Saúde Joaquim Venâncio, Fundação Oswaldo Cruz (EPSJV/Fiocruz). Av. Brasil, 4365, Manguinhos. Rio de Janeiro, RJ, Brasil.

21040-360.vejoana@ fiocruz.br; crismm@

fiocruz.br; ingriddavila@ fiocruz.br; mlopes@ 


\section{Introdução}

Desde 2008, a Escola Politécnica de Saúde Joaquim Venâncio (EPSJV/Fiocruz) vem desenvolvendo o Curso Técnico de Agente Comunitário de Saúde (CTACS), seguindo a orientação do Referencial Curricular, estabelecido pelo Ministério da Educação, em conjunto com o Ministério da Saúde ${ }^{1}$. O curso tem, como eixo norteador, a discussão da educação e saúde, desenvolvida principalmente a partir das contribuições do campo da Educação Popular em Saúde. Nesse sentido, propicia, a partir das discussões em sala de aula, uma aproximação crítica do corpo docente com o trabalho desenvolvido pelos alunos e sua ação educadora.

Durante os processos formativos empreendidos, tem chamado a atenção dos professores o pouco investimento das equipes de Saúde da Família do Rio de Janeiro no trabalho educativo dos Agentes Comunitários de Saúde (ACS), em especial os de caráter coletivo, como os grupos de promoção de saúde. Além disso, percebeu-se que, ao desenvolverem atividades educativas, formal ou informalmente, os ACSs tendiam a reproduzir práticas verticais, legitimadas pelo saber biomédico.

Essas questões também estão mencionadas em alguns estudos sobre a Estratégia Saúde da Família (ESF) e sobre o trabalho do ACS no Brasil. Em pesquisa realizada por Bornstein e Stotz ${ }^{2}$, ao abordar o tipo de mediação educativa realizada pelos agentes de saúde na Maré, percebeu-se que as cobranças institucionais, feitas aos agentes, "privilegiam a forma de mediação convencedora, na medida em que pretendem convencer a população a seguir comportamentos e atitudes considerados corretos" (p. 476), ao invés de trabalhar numa perspectiva de mediação transformadora. Esta última é entendida como

[...] uma mediação que contribui para novas práticas em saúde, abertas ao reconhecimento da existência de diferentes saberes sobre a saúde, sejam eles médicos ou não médicos; considera os limites do conhecimento científico sobre saúde no que se refere às causas das doenças e à sua cura e reconhece a importância da experiência da enfermidade e do conhecimento comum das pessoas² (p. 464).

Em outra pesquisa, realizada com os alunos da primeira turma do CTACS/EPSJV ${ }^{3}$, constatou-se que as equipes de saúde desses alunos desenvolviam poucas atividades educativas na comunidade, os temas abordados estavam geralmente relacionados a doenças e a sua principal conotação era convencedora. Ao mesmo tempo, percebeu-se que os grupos, espontaneamente organizados, apresentam um potencial de mediação educativa que, embora não previsto, favorece a abordagem de assuntos não necessariamente relacionados a questões biomédicas.

Diante das questões aqui apontadas e do contexto recente de institucionalização da Política Nacional de Educação Popular em Saúde ${ }^{4}$, pretende-se, neste texto, discutir as prescrições e atribuições dos ACSs, os desafios de sua atuação profissional e as perspectivas de desenvolvimento de seu trabalho como educador.

Busca-se apresentar os fatores que facilitam ou dificultam a realização do trabalho educativo e os aspectos que reforçam a educação pautada pelo saber biomédico e pela perspectiva tradicional de transmissão de conhecimento. Por fim, apresentam-se possíveis contribuições da Educação Popular em Saúde para a constituição da práxis educadora dos ACSs.

\section{Percurso metodológico}

A construção do presente artigo teve por base o levantamento de artigos em periódicos sobre o trabalho educativo desses trabalhadores, a partir das seguintes questões: qual o trabalho prescrito aos ACSs? Como é realizado o trabalho educativo? Também se pautou na experiência das autoras na formação técnica dos ACSs, mais especificamente no que se refere ao planejamento e execução do eixo Educação em Saúde, que é um dos componentes curriculares do CTACS.

As autoras participaram da coordenação pedagógica e/ou como professoras do eixo Educação em Saúde, nas turmas do Curso Técnico de Agente Comunitário de Saúde, realizado pela EPSJV, que formou 215 alunos, distribuídos em oito turmas, no período entre 2008 a 2012. 
A pesquisa bibliográfica foi realizada inicialmente na Scielo, em janeiro de 2013, com o descritor Agente Comunitário de Saúde. Nessa busca foram encontradas 91 publicações das quais 32 foram selecionadas por mencionarem, em seu resumo ou entre as palavras-chave, práticas educativas, Educação em Saúde, promoção da saúde e prevenção de doenças. Realizou-se pesquisa complementar na base de dados Lilacs, onde foram identificados artigos com texto completo com o termo Agente Comunitário de Saúde e assuntos: Educação em Saúde, promoção da saúde, saúde da família e programa saúde da família. Foram encontradas noventa publicações, das quais foram selecionadas seis que não constavam na seleção anterior.

\section{Políticas de saúde e trabalho do ACS: uma breve construção histórica}

O Programa Nacional de Agentes Comunitários de Saúde foi lançado no ano de 1991, vindo a se chamar Programa de Agentes Comunitários de Saúde no ano de 1992. A implantação do referido Programa começou pelos estados do Nordeste, priorizando-se as ações da área materno-infantil. Essas experiências, assim como um conjunto de experiências locais de organização da Atenção Primária à Saúde no Brasil, delinearam o lançamento do Programa de Saúde da Família no ano de $1994^{5}$.

A partir de 1996, o Ministério da Saúde passou a identificar a Saúde da Família como uma estratégia de reorganização da atenção à saúde no país, visando contribuir no aprimoramento e na consolidação do Sistema Único de Saúde, a partir da reorientação da assistência ambulatorial e domiciliar. O status de Estratégia buscava o rompimento com a expressão "Programa de Saúde da Família", pelo caráter transversal e focalizado, atribuído aos programas 6 .

$\mathrm{Na}$ Política Nacional de Atenção Básica - $\mathrm{PNAB}^{7}$, a reorganização da atenção à saúde foi entendida no sentido da substituição do modelo tradicional de assistência, com racionalidade biomédica, voltado para a cura de doenças e "hospitalocêntrico", por outro, cujas principais características são: o enfoque sobre a família, a partir de seu ambiente físico e social, como unidade de ação; a adscrição de clientela por meio da definição de território de abrangência da equipe; a estruturação de equipe multiprofissional; a ação preventiva em saúde; a detecção de necessidades da população ao invés da ênfase na demanda espontânea; a atuação intersetorial com vistas à promoção da saúde.

A nova $\mathrm{PNAB}^{8}$, aprovada em outubro de 2011, retoma a importância da Estratégia Saúde da Família (ESF) na reorganização da atenção básica no país "de acordo com os preceitos do Sistema Único de Saúde" (p. 54), e define a atenção básica como "primeiro ponto de atenção e principal porta de entrada do Sistema" (p. 24), a partir da organização das Redes de Atenção à Saúde (RAS) ${ }^{(e)}($ será e) como estratégia de cuidado integral e direcionado às necessidades de saúde da população. A Portaria ressalta ainda que a Atenção Básica "é desenvolvida por meio de práticas de cuidado e gestão, democráticas e participativas, sob a forma de trabalho em equipe" (p. 19).

Franco e Merhy ${ }^{9}$ mencionavam as contradições da proposta do PSF, por sua centralidade nos conceitos de território e ambiente, com pouca incursão na clínica

(e) "As RAS constituem-se em arranjos organizativos formados por ações e serviços de saúde com diferentes configurações tecnológicas e missões assistenciais, articuladas de forma complementar e com base territorial8" (p. 25). e no cuidado ao usuário. Essa opção poderia reproduzir, ao longo do tempo, a dinâmica "médico-centrada" ou "procedimento-centrada", característica dos serviços de saúde. 
Apesar das potencialidades da ESF para a ampliação do acesso, Sousa e Hamann ${ }^{10}$ destacam que os desafios para a reorientação do modelo biomédico persistem, o que caracterizaria a ESF como uma agenda incompleta. Giovanella et al..$^{11}$ mencionam alguns dos problemas dessa agenda que são a falta de garantia da integralidade da atenção e de continuidade do cuidado, a incipiente realização de ações intersetoriais, bem como a formação e atuação profissional em saúde, ainda, centradas nos modelos de saber e práticas médicas hegemônicas.

Tanto o Pacs como o PSF/ESF têm em comum o ACS como elemento inovador no quadro funcional. O investimento nessa inovação tem sido frequentemente associado aos resultados positivos do trabalho dos agentes no enfrentamento a determinados problemas de saúde, às indicações dos Organismos Internacionais para expansão de cobertura da Atenção Primária em Saúde (APS), e à possibilidade da constituição da competência cultural como um dos atributos derivados da APS ${ }^{12}$.

A competência cultural compõe um dos atributos da APS, na medida em que se propõe como cenário de atuação o contexto das famílias e das comunidades. Isso envolve "o entendimento das condições de vida do paciente, da dinâmica familiar e dos antecedentes culturais referentes à comunidade na qual o paciente vive"12 (p. 51), bem como a "consciência das necessidades de saúde na comunidade e a colaboração com outros setores para desencadear mudanças positivas de saúde" 12 (p. 53).

No Brasil, a necessidade de aproximação entre a ESF e a realidade das famílias e comunidades revelava um paradoxo, dada a tradição dos modelos assistenciais anteriores. No entanto, segundo a PNAB, a Estratégia Saúde da Família tem o papel de reorganizar a atenção básica no País ${ }^{8}$ (p. 54).

Ainda que entre as atribuições de todos os profissionais da equipe de atenção básica existam atribuições inovadoras como, por exempo, a de promover a mobilização e a participação da comunidade, buscando efetivar o controle social ${ }^{8}$ (p. 45), a maior ênfase sobre a aproximação com a população é feita no trabalho de agente comunitário, trabalhador cuja especificidade é residir na comunidade atendida pela unidade de saúde. Entre suas atribuições específicas, consta

Desenvolver atividades de promoção da saúde, de prevenção das doenças e agravos e de vigilância à saúde, por meio de visitas domiciliares e de ações educativas individuais e coletivas nos domicílios e na comunidade $[\ldots]^{8}$ (p. 49).

atributo de difícil incorporação pelos profissionais do setor saúde, impregnados pela lógica biologicista em suas trajetórias formativa e profissional.

\section{As prescrições do trabalho para o ACS}

Ainda que existissem agentes de saúde atuando em vários pontos do Brasil, antes da criação das políticas públicas de saúde que os inserem no SUS, é possível dizer que são essas políticas que efetivamente dão a esses agentes o status de trabalhadores. É a partir delas que aparece formalmente a ocupação de ACS.

Nesse sentido, a implementação e as formas de avaliação dessas políticas irão desenhar o trabalho dos agentes e prescrever suas atividades em caráter nacional. Além disso, sua difusão e repercussão propiciaram o crescimento e o fortalecimento da categoria profissional dos ACSs, impulsionando o movimento desses trabalhadores pelo reconhecimento e a regulamentação de sua profissão.

No que se refere à regulamentação da profissão, Morosini et al. ${ }^{13}$ analisam os embates que se deram de forma geral no nível do legislativo e do executivo em relação a projetos de regulamentação da prática dos ACSs. Em 1997, deu-se a publicação da Portaria nº 1.886 que aprovava as normas e diretrizes do Programa de Agentes Comunitários de Saúde (Pacs) e do Programa de Saúde da Família (PSF). Entre suas diretrizes operacionais, consta que "O Agente Comunitário de Saúde deve desenvolver atividades de prevenção das doenças e promoção da 
saúde, através de visitas domiciliares e de ações educativas individuais e coletivas nos domicílios e na Comunidade"6 (p. 4).

Ainda no parágrafo seguinte, menciona-se que ao ACS é vedado o desenvolvimento de atividades típicas do serviço interno das unidades básicas de saúde. Essa definição permaneceu presente nos documentos posteriores, tais como o Decreto $n^{\circ} 3189^{14}$, a Lei $n^{\circ} 10.507^{15}$ e a Lei $n^{\circ} 11.350^{16}$, onde a atuação do ACS é definida como centrada na promoção da saúde e na prevenção de doenças, para as quais a ação educativa é fundamental no nosso entender.

Esse mesmo enfoque está presente no referencial curricular para o Curso Técnico de Agente Comunitário de Saúde ${ }^{1}$, construído pelo Ministério da Saúde em conjunto com o Ministério da Educação.

A Portaria que institui a Política Nacional de Atenção Básica ${ }^{8}$ menciona como atribuições do ACS: trabalhar com adscrição de famílias; cadastrar as pessoas de sua microárea; orientar famílias quanto à utilização dos serviços de saúde; realizar atividades programadas e de atenção à demanda espontânea; acompanhar por meio de visita domiciliar, todas as famílias e indivíduos sob sua responsabilidade; desenvolver ações que busquem a integração entre a equipe de saúde e a população adscrita; desenvolver ações de promoção da saúde, de prevenção das doenças e agravos e de vigilância à saúde, por meio de visitas domiciliares e de ações educativas individuais e coletivas nos domicílios e nas comunidades; estar em contato com as famílias, desenvolvendo ações educativas, visando à promoção da saúde, à prevenção das doenças e ao acompanhamento das pessoas com problemas de saúde, bem como ao acompanhamento das condicionalidades do Programa Bolsa-Família ou de qualquer outro programa similar de transferência de renda. A referida Portaria destaca ainda que "é permitido ao ACS desenvolver outras atividades nas Unidades Básicas de Saúde, desde que vinculadas às atribuições"8 (p. 50).

É possivel considerar que a maior parte das atividades prescritas para o ACS, a partir das leis e portarias nacionais, ressalta a dimensão do trabalho educativo. Porém, essa dimensão tem sido limitada pelas demandas burocráticas e pelos modelos de avaliação de seu trabalho. Para Bornstein e Stotz ${ }^{2}$ e Brigadão e Gonçalves ${ }^{17}$, o fato das atividades de promoção da saúde não serem consideradas nos relatórios de produtividade e não terem espaço para seu relato no Sistema de Informação da Atenção Básica (Siab) representa, por exemplo, uma contradição com as diretrizes da Estratégia Saúde da Família.

Ao problematizarem o formato da avaliação da Atenção Básica (AB), Fonseca et al. ${ }^{18}$ corroboram com os outros autores e sugerem que o papel central, ocupado pelo SIAB, bem como o viés produtivista dos processos avaliativos da $A B$, acabam por contribuir para a manutenção do modelo de atenção assistencial, em contradição com a missão de reorientação atribuída à ESF.

Assim, a análise desse conjunto de atribuições e das possíveis contradições nos processos de prescrição, informação e avaliação da ESF evidenciam a amplitude das atividades prescritas para o ACS. Esse caráter ampliado e inespecífico do trabalho tem favorecido a construção de diferentes sentidos para sua atuação profissional. A impossibilidade de realização total e irrestrita de todas essas atribuições, e o argumento de que a prática na ESF deve considerar as especificidades locais, legitimam um cenário em que o trabalho do ACS tem se constituído, predominantemente, a partir das necessidades e demandas dos serviços de saúde depositadas sobre ele.

Algumas prescrições do trabalho do ACS, no nível local, puderam ser observadas em sala de aula durante o eixo Educação em Saúde do CTACS-EPSJV, onde a maior parte dos alunos relatava a falta de espaço para a realização do trabalho educativo com a população, uma vez que o "turno" de promoção da saúde havia sido retirado de sua agenda semanal. Para os alunos, o trabalho educativo realizado até mesmo nas visitas domiciliares estava centrado nas doenças:

"Eu estou há 8 anos escutando que o ACS é o "elo de ligação", aprendi que o ACS é o mediador entre a comunidade e os serviços de saúde, que temos potencial para o desenvolvimento de um trabalho educativo, que a ESF é um modelo que não tem um enfoque biologicista e centrado na patogenia". [depoimento realizado em sala de aula ACS1] 
"Tudo isso se perdeu com a entrada das Organizações Sociais ${ }^{(f)}$. O modelo ESF se descaracterizou por completo: foca-se a doença e o médico, o ACS vive mais no computador do que na rua, as reuniões são para 'despejar' mais trabalho, temos rodízio para recepção, não temos mais tempo de ouvir pacientes. Existe um descontentamento geral. São metas atrás de metas e as pessoas viraram números. Tenho que colocar as metas, as prioridades no sistema: HA, DIA, gestantes, crianças até 2 anos. Não sobra tempo para a promoção. Talvez sejam meus últimos momentos na ESF, pois não tenho conseguido me adequar ao sistema". [depoimento realizado em sala de aula ACS2]

A realidade de incorporação de novos modelos de gestão a partir de configurações de parceria entre os setores público e privado, bem como a adoção de modelos tipicamente gerenciais têm ampliado os mecanismos de avaliação, pautados pela lógica produtivista do trabalho. No caso específico do Rio de Janeiro, essas questões se explicitam pela cobrança de dedicação de horas de trabalho para a recepção/acolhimento dos usuários nos serviços, assim como pela impossibilidade de realização de grupos educativos como parte de sua agenda de trabalho semanal.

Em levantamento realizado em sala de aula sobre as dificuldades dos ACS em exercer o trabalho educativo, chama atenção o destaque dado à falta de tempo $e$ de espaço adequado, dois elementos essenciais para a realização desse trabalho. Nas palavras de uma ACS:

"Infelizmente hoje não temos tanto tempo para nos dedicarmos para educação e promoção à saúde, embora esse seja o foco principal da saúde da família. [...] A realidade só quem vive é quem vê!". (ACS3)

Assim, o caráter normativo e a excessiva burocratização do trabalho dos ACSs contribuem para a redução do potencial criativo que, em um primeiro momento, justificou o reconhecimento e a regulamentação dessa profissão. Inicialmente, esperava-se que o trabalho dos ACSs pudesse se pautar pela ampliação da competência cultural das equipes de saúde que, por toda a racionalidade técnica e científica, pouco conseguia dialogar com a população.

Entretanto, a realidade evidenciada, nesses depoimentos e em sala de aula, indica que a complexa lógica de incorporação desse trabalhador ao cenário da atenção à saúde tem produzido o aprisionamento de suas práticas, reproduzindo a lógica assistencial hegemônica do setor.

\section{Desafios da atuação profissional do ACS}

Apesar da reiteração da centralidade da prevenção de doenças e da promoção da saúde no trabalho do agente de saúde na legislação, vários são os estudos sobre o processo de trabalho dos ACSs: Koda et al..$^{19}$ (2012); Brigadão e Gonçalves ${ }^{17}$; Bornstein e Stotz ${ }^{2}$; Nascimento e Correa ${ }^{20}$; Araújo e Assunção ${ }^{21}$, que apontam para a sobrecarga de trabalho e o desvio de função, como fatores que dificultam a realização do trabalho educativo.

Bornstein e Stotz ${ }^{2}$, em estudo realizado no Complexo da Maré, no município do Rio de Janeiro, assim como Nascimento e $\mathrm{Correa}^{20}$, em estudo realizado em Campinas, e Araújo e Assunção21, em artigo sobre a atuação do agente comunitário na cidade de Divinópolis, Minas Gerais, mencionam a burocratização do trabalho, a realização de atividades administrativas, a organização de (f) As Organizações Sociais mencionadas referem-se a um modelo de parceria adotada pelo governo do município do Rio de Janeiro para a gestão de unidades de saúde, por meio de pessoas jurídicas de direito privado. 
filas, cobertura à ausência de outros profissionais e a organização da coleta de sangue, como exemplo de atividades que ocupam o tempo do agente de saúde e dificultam o desempenho do papel de articulador e de educador desse profissional. Brigadão e Gonçalves ${ }^{17}$, em estudo realizado na zona Leste de São Paulo, citam, como exemplo, a vigilância sanitária dos animais de rua, a fiscalização de caixas d'água.

Os autores também identificam a dificuldade do ACS romper com o modelo tradicional, centrado na cura de doenças, focado no indivíduo e culpabilizando-o por sua situação de vida e saúde. Em estudo recente, Filgueiras e Silva ${ }^{22}$ apontam que os ACSs reconhecem como objeto de seu trabalho a comunidade e seus problemas de saúde. Entretanto, de acordo com a pesquisa realizada em Volta Redonda, RJ,

[...] o foco da $V D(g)$ está na doença, o que dificulta a realização de estratégias

(g) Visita domiciliar. que favoreçam a promoção à saúde em seu conceito mais amplo, o de completo bem estar físico, social e mental, e não somente a ausência de doenças. ${ }^{22}$ (p. 911)

Seguindo ainda a mesma argumentação, Gomes et al. ${ }^{23}$, em pesquisa realizada no município de Cajuri (MG), observam que o trabalho de orientação feito pelos agentes acontece basicamente de forma individualizada, centrada no reforço da assistência médica. Em depoimentos, os ACSs apontaram que, em vários momentos, as VDs são associadas à entrega de medicamentos, resultados de exames e ao agendamento de consultas.

Ferraz e Aerts ${ }^{24}$, Baralhas e Pereira ${ }^{25}$ e Coriolano e Lima ${ }^{26}$, em estudos realizados, respectivamente, em Porto Alegre, interior de São Paulo e Ceará, apontam que a Visita Domiciliar está, de forma geral, direcionada à prevenção de doenças e relacionada aos programas desenvolvidos pelas unidades de saúde cujo caráter é, sobretudo, biomédico e individual.

\section{As dimensões do trabalho educativo: entre as prescrições e a atuação profissional do ACS}

O campo das práticas de Educação em Saúde se constitui como espaço por excelência de aproximação da ação médica com o pensar e o fazer cotidiano da população ${ }^{27}$. No entanto, é preciso ressaltar que essa aproximação pode ser construída de diferentes maneiras, a partir de formas diversas de entender e de se relacionar com o saber científico e com os usuários do sistema de saúde.

Inserida no contexto das práticas autoritárias, que marcaram a saúde pública em nosso país até a década de 1970, a Educação em Saúde, no Brasil, surge com propostas extremamente verticais e comprometidas com o controle das populações desfavorecidas e com a expansão dos interesses capitalistas. O saber biomédico, tomado como verdade indiscutível, legitima a prescrição de condutas para uma população considerada ignorante e, mais do que promover saúde, garante a manutenção do status quo.

O Movimento da Reforma Sanitária rompe com esses valores, e comprometido com a transformação social, propõe novas formas de aproximação da população e de seu saber. Entretanto, no cotidiano dos serviços de saúde, relações hierarquizadas entre os profissionais de saúde e o lugar do ainda incontestável saber biomédico atravessam as tentativas de construção de novas práticas de educação e saúde.

Assim, apesar da retórica de reorientação no modelo assistencial a partir da ESF, a atenção à saúde e a Educação em Saúde, vivenciadas nesse cenário, 
ainda têm como eixo central a reprodução da prática médica tradicional, pautada pela transmissão de conhecimentos e pela prescrição de hábitos saudáveis.

Francolli e Almeida ${ }^{28}$ destacam que

O ACS não foca sua ação no que existe de positivo, mas na perspectiva da doença (mudança de hábito para não ficar doente), da carência, do que falta, distanciando-se da perspectiva da Promoção da Saúde, que envolve o desenvolvimento da autonomia e consciência do indivíduo e coletividade (seguida de capacitação dirigida) com vistas à tomada de decisões sobre suas necessidades de saúde e o exercício da cidadania. (p. 142)

Também Trapé e Soares ${ }^{29}$ constataram, por meio de grupos focais realizados com ACSs em São Paulo, que grande parte das concepções de educação que permeiam o trabalho realizado por esses profissionais é pautada pela transmissão de informações. A população é entendida como público-alvo, passiva e que deve aceitar as orientações dos técnicos.

No que se refere à atuação educativa do ACS, devem ser destacadas algumas particularidades do "encontro" entre saberes. Esse profissional transita entre saberes distintos, o popular e o científico, o que confere potência a seu trabalho e implica no desafio de conciliar posições diversas: adquiriu um saber técnico, que lhe dá um status profissional, e, simultaneamente, tem acesso aos saberes advindos da classe popular, a qual pertence. Ao mesmo tempo que tem como suporte um saber valorizado socialmente, deve preservar o saber popular, que seria sua marca.

Zanchetta et al..$^{30}$ (p. 1) apontam a duplicidade de funções do ACS aos olhos da comunidade, pois são "a voz da população e, simultaneamente a presença do Estado". Eles possuem um saber em relação à população, que reconhecem como importante para o seu trabalho. Destaque-se, por exemplo, que, em levantamento realizado em sala de aula, os ACSs apontaram, como facilitadora de suas práticas educativas, a convivência com a população, o que possibilita o conhecimento de sua linguagem e de seus problemas.

Por outro lado, sua atuação profissional possui uma dimensão diretamente ligada ao seu papel como representante do Estado. Nesse sentido, são cobrados a orientar suas atividades, basicamente segundo as prioridades estabelecidas nos serviços. Esse saber técnico também é mais valorizado socialmente, e não deixa de ser uma maneira por meio da qual legitimam o seu trabalho com a população.

Diante desse quadro, é importante investigar de que forma é possível aos ACSs realizar uma mediação transformadora, que se fundamenta na experiência e nas condições de vida da população e tem por pressuposto a valorização das práticas e conhecimentos populares. Como afirma Garcia ${ }^{31}$ ( $p$. 113) "não se trata de os grupos populares chegarem ao conhecimento do agente [educador] nem do inverso, já que é nessa assimetria de conhecimentos díspares que se dá o processo educativo".

Para a realização desse encontro de saberes, é preciso, entretanto, que os ACSs possam refletir sobre suas práticas, sobre os dilemas que envolvem a relação entre o Estado e as demandas das classes populares, e, portanto, sobre os interesses que mobilizam o seu trabalho. A respeito dessa atitude reflexiva, que se compõe como um devir praxiológico, Vázquez ${ }^{32}$ (p. 223) ressalta que a "atividade própria do homem não pode reduzir-se à sua mera expressão exterior, e que dela forma parte essencialmente a atividade da consciência".

A práxis compõe um exercício cotidiano dos sujeitos históricos e dialoga com a constituição de agentes.

Agente é o que age, o que atua e não o que tem apenas a possibilidade ou disponibilidade de atuar ou agir. Sua atividade não é potencial, mas sim atual. Ocorre efetivamente sem que possa ser separada do ato ou do conjunto de atos que a constituem ${ }^{32}$ (p. 220).

Segundo Queirós e Lima ${ }^{33}$, as contradições presentes na atuação dos ACSs podem ser compreendidas, dentre outros aspectos, a partir das transformações nas expectativas em relação ao seu trabalho, com a maior institucionalização desses trabalhos e de suas novas formas de recrutamento. O estudo desses autores esclarece que, nas décadas de 1970 e 1980, as formas de recrutamento estavam associadas às organizações comunitárias e possibilitavam um maior envolvimento dos ACS nas lutas populares. 
Para nós, o processo de institucionalização, e com isso a forma de recrutamento dos ACS na atualidade, enfraqueceu seu vínculo com a comunidade. No entanto, o que vimos, tanto na pesquisa de campo como na rotina de trabalho da gestão da rede básica, é que, de forma persistente, esse comprometimento continua existindo ${ }^{33}$ (p. 277).

De qualquer maneira, é preciso ressaltar que

[...] o ACS não é mais, como quando ainda era denominado agente de saúde, um braço do movimento popular na luta pela garantia do direito à saúde. Embora com atribuições semelhantes, ele passa a ter uma nova inserção no campo da saúde, com base na qual a sua atuação se desloca, com efeitos interessantes no que diz respeito à possibilidade de maior dedicação e envolvimento, mas que transforma seu vínculo com a população e, de certa maneira, redireciona a sua prática ${ }^{34}$ (p. 177).

Assim, a mediação transformadora, que se coloca como uma forma desejável de atuação dos ACSs junto à população, é parte de um exercício de reflexão sobre as capturas e possibilidades que resultam do processo de institucionalização de seu trabalho, bem como da necessidade do resgate de seu diálogo com sua classe de origem. Ou seja, a mediação transformadora que os ACSs podem exercer em seu trabalho parte, possivelmente, de sua práxis política, de "sua transformação como ser social, destinado a mudar suas relações econômicas, políticas e sociais"32 (p. 230-1). Assim como de sua práxis social que "é a atividade de grupos ou classes sociais que leva a transformar a organização e a direção da sociedade, ou a realizar certas mudanças mediante a atividade do Estado." 32 (p. 231).

\section{Possibilidades da Educação Popular em Saúde para a consituição do ser educador}

Integrar a dimensão política do trabalho ao cotidiano de atividades da ESF envolve mais do que levar em consideração o conhecimento do ACS sobre o local e a população atendida. Na realidade, esse processo envolve tornar essas atividades mais complexas, ao considerar que cuidar e promover saúde não significa prescrever remédios e condutas saudáveis. É preciso desnaturalizar as condições de vida e saúde da população e problematizar as relações sociais, os modos de existência e as diferentes formas de adoecimento.

Nesse sentido, o trabalho do agente precisa ser muito mais amplo do que simplesmente fazer o levantamento e acompanhamento de situações específicas, discriminadas pela ESF (como gestação ou hipertensão) e difusão de informação sobre prevenção de doenças. Os fundamentos teórico-metodológicos da Educação Popular em Saúde (EPS) poderiam contribuir nesse processo, subsidiando transformações nas relações e nas práticas educativas, realizadas no âmbito da atenção à saúde individual e coletiva.

Ao tomar como princípio a construção conjunta do conhecimento e o diálogo entre diferentes saberes, a EPS propõe que se parta da escuta do outro e da valorização dos seus saberes, potencializando o encontro com a diversidade. Mas esse é apenas um ponto de partida de um processo que propicia a discussão dos problemas vividos pela população, com todas as suas contradições.

A experiência prévia dos sujeitos é reconhecida e contribui para a identificação das situações limite presentes no cotidiano e das potencialidades para transformá-las por meio de ações para sua superação. [...] O sujeito, por sua vez, também se transforma na ação de problematizar e passa a detectar novos problemas na sua realidade e assim sucessivamente ${ }^{4}$ (p. 16).

Os princípios da EPS implicam um posicionamento e um modo de agir que criticam o formato tradicional da Educação em Saúde, que "tem sido um instrumento de dominação, de afirmação de um saber dominante, de responsabilização dos indivíduos pela redução dos riscos à saúde" 35 (p. 260).

Esse enfoque educativo, pautado pela prescrição de modos de viver saudáveis, caracteriza uma perspectiva restrita de promoção da saúde, que tem sido frequentemente incorporada pelos discursos das políticas nacionais e, especialmente por agências internacionais, como a Organização Mundial de Saúde. 
É importante relembrar que as relações entre desigualdade, iniquidade e determinação social não podem ser reduzidas a uma simples análise circular de causa e consequência. A complexidade da sociedade e os seus não menos complexos problemas não podem ser reduzidos a fatores sociais isolados, e tampouco essas situações podem ser reduzidas a fatores de vulnerabilidade e risco ${ }^{36}$ (p. 444).

A Educação Popular pode ser entendida como uma proposta que dialoga com a perspectiva ampliada da promoção da saúde, fundamentada no exercício de enfrentamento dos determinantes e condicionantes do processo saúde-doença. Ou seja, uma perspectiva de atuação pautada pela valorização da vida humana e pelo diálogo revelador dos processos de desigualdade e injustiça social, potencialmente adoecedores.

O estabelecimento de vínculos entre os profissionais, especialmente os ACSs e a população, tem se constituído como fundamental para a construção de novas relações no setor, ainda que isso não seja suficiente para mudar a lógica da atenção à saúde. É importante ressaltar que tais relações não devem se constituir apenas como escolha pessoal ou rota de fuga dos trabalhadores.

Albuquerque e Stotz ${ }^{35}$ destacam que, embora o discurso das práticas educativas no Saúde da Família seja valorizado por órgãos gestores nacionais, não foram desenvolvidas propostas específicas para o desenvolvimento dessas ações.

No âmbito dos municípios, tem sido mais comum o relato de experiências utilizando o referencial da educação popular nas práticas de saúde, porém levadas a cabo por iniciativa dos próprios profissionais, muitas vezes até em contraposição aos gerentes municipais ${ }^{35}$ (p. 261).

Assim, não parece que a viabilização dessas atividades educativas nem mesmo a adoção de discursos sobre a Educação Popular de forma instrumental, restrito ao diálogo com os usuários, sejam suficientes para enfrentar o conjunto de desafios da atenção à saúde no Brasil. A Educação Popular em Saúde pressupõe, simultaneamente, a democratização das relações e a redistribuição de poder, demandando a construção de novas interações dos trabalhadores com o seu trabalho e novos arranjos de gestão e participação nos serviços de saúde.

Ressalta-se que a Educação Popular, usualmente centrada na atuação em comunidades, pode contribuir também para a formação de profissionais de saúde e para a organização de políticas públicas pautadas pelos direitos da população ${ }^{37}$.

\section{Considerações finais}

Entendemos que a Educação Popular em Saúde pode contribuir com o resgate das relações entre usuários, trabalhadores e gestores do SUS, uma tríade que tem o ACS como um articulador em potencial. Entretanto, em função de toda a discussão empreendida até aqui, acreditamos que se trata apenas de um potencial, dados os contextos de precarização e excessiva normatização de seu trabalho e de sua formação.

Nesse sentido, as possibilidades de os ACSs realizarem um trabalho educativo em saúde por meio de mediações transformadoras esbarram em inúmeras dificuldades. Como visto, a maneira como esses profissionais têm sido incorporados ao modelo de atenção à saúde limita a sua atuação como agente transformador e fomentador da participação popular, pois embora lhes sejam atribuídos esses papéis, a estruturação dos serviços e as formas de gestão impulsionam-os a assumirem funções características da assistência em saúde tradicional.

Evidentemente não é suficiente que no âmbito do discurso se destaque o papel transformador do ACS, quando a estrutura em que ele está inserido ainda é, em muito, conservadora. Ao mesmo tempo, consideramos que nem mesmo as intervenções educativas, baseadas na EPS, garantirão transformações na sociedade, embora sejam elas potencializadoras de modificações.

Ainda assim, cabe-nos identificar as possibilidades de pautar a atuação dos ACSs a partir de uma concepção de Educação Popular em Saúde. Nesse sentido, a criação de espaços de expressão do saber 
dos agentes e análise crítica do trabalho educativo realizado seriam fundamentais para se repensar constantemente a sua práxis.

Em nossa experiência no CTACS, foi possível experimentar Educação Popular incorporada ao ensino formal, nas relações entre os educadores do curso e entre educadores e educandos. Além disso, a EPS constituiu-se num referencial construído com os alunos para repensarem seu modo de fazer no trabalho. Entendemos como parte da atividade do ACS não só o diálogo crítico com as comunidades onde atua/reside, como também a reflexão sobre sua própria condição histórica. Incorporar a Educação Popular na educação dos profissionais de saúde tem se constituído como uma oportunidade ousada e envolvente. Foi à luz dessa experiência e de seus significados que constituímos esta reflexão.

\section{Colaboradores}

Os autores participaram, igualmente, de todas as etapas de elaboração do artigo.

\section{Referências}

1. Ministério da Saúde. Ministério da Educação. Referencial curricular para curso técnico de Agentes Comunitários de Saúde: área profissional saúde [Internet]. Brasília (DF): Ministério da Saúde; 2004 [acesso 2013 Abr 28]. Disponível em: http://bvsms.saude.gov. $\mathrm{br} / \mathrm{bvs} /$ publicacoes/referencial_Curricular_ACS.pdf.

2. Bornstein VJ, Stotz EN. O trabalho dos agentes comunitários de saúde: entre a mediação convencedora e a transformadora. Trab Educ Saude. 2008/2009;6(3):457-80.

3. Bornstein VJ, Matta GC, David H. O processo de trabalho do agente comunitário de saúde e sua incidência sobre a mudança do modelo de atenção em saúde. In: Monken $M$, Dantas AV, organizadores. Estudos de Politecnia e Saúde. Rio de Janeiro: EPSJV; 2009. v. 4. p. 191-219.

4. Política Nacional de Educação Popular em Saúde [Internet]. Brasília (DF): Ministério da Saúde. Secretaria de Gestão Estratégica e Participativa; 2012 [acesso 2013 Abr 3]. Disponível em: www.cnts.org.br/geral/Arquivo/PNEPS\% 20SUS\% 20março\% 202012.doc

5. Viana ALD, Dal Poz MR. A Reforma do Sistema de Saúde no Brasil e o Programa de Saúde da Família. Physis. 2005;15 Supl.:225-64.

6. Portaria $n^{\circ} 1.886$, de 18 de dezembro de 1997. Aprova as Normas e Diretrizes do Programa de Agentes Comunitários de Saúde e do Programa de Saúde da Família. Brasília (DF): Ministério da Saúde; 1997 [acesso 2013 Fev 18]. Disponível em: http://dtr2004. saude.gov.br/susdeaz/legislacao/arquivo/21_Portaria_1886_de_18_12_1997.pdf

7. Ministério da Saúde. Departamento de Atenção Básica. Política Nacional de Atenção Básica [Internet]. Brasília (DF): Ministério da Saúde; 2006 [acesso 2013 Fev 18]. Disponível em: http://bvsms.saude.gov.br/bvs/publicacoes/politica_nacional_atencao_basica_2006.pdf

8. Ministério da Saúde. Secretaria de Atenção à Saúde. Departamento de Atenção Básica. Política Nacional de Atenção Básica [Internet]. Brasília (DF): Ministério da Saúde; 2012 [acesso 2013 Mar 9]. Disponível em: http://189.28.128.100/dab/docs/publicacoes/geral/pnab.pdf

9. Franco T, Merhy E. PSF: contradições e novos desafios. In: Conferência Nacional de Saúde [Internet]. Tribuna Livre 2000 [acesso 2013 Mar 1]. Disponível em: http://www.uff. $\mathrm{br} /$ saudecoletiva/professores/merhy/artigos-17.pdf

10. Sousa MF, Hamann EM. Programa Saúde da Família no Brasil: uma agenda incompleta? Cienc Saude Colet. 2009;14(1):1325-35.

11. Giovanella L, Mendonça MHM, Almeida PF, Escorel S, Senna MCM, Fausto MCR, et al. Saúde da família: limites e possibilidades para uma abordagem integral de atenção primária à saúde no Brasil. Cienc Saude Colet. 2009;14(3):783-94. 
12. Starfield B. Atenção Primária: equilíbrio entre necessidades de saúde, serviços e tecnologia. Brasília (DF): Unesco, Ministério da Saúde; 2002.

13. Morosini MV, Corbo AD, Guimarães CC. O agente comunitário de saúde no âmbito das políticas voltadas para a atenção básica: concepções do trabalho e da formação profissional. Trab Educ Saude. 2007;5(2):287-310.

14. Decreto n. 3.189, de 4 de outubro de 1999. Fixa diretrizes para o exercício da atividade de agente comunitário de saúde e dá outras providências. Diário Oficial da União [Internet]. 5 Out 1999 [acesso 2013 Abr 28]. Disponível em: http://www.planalto.gov.br/ ccivil_03/decreto/D3189.htm

15. Lei n ${ }^{\circ}$. 10.507, de 10 de julho de 2002. Cria a profissão de agente comunitário de saúde e dá outras providências. Diário Oficial da União [Internet]. 11 Jul 2002 [acesso 2013 Abr 18]. Disponível em: http://www2.camara.leg.br/legin/fed/lei/2002/lei-1050710-julho-2002-468370-norma-pl.html

16. Lei $\mathrm{n}^{\circ} 11.350$, de 5 de outubro de 2006. Regulamenta o $\S 5^{\circ}$ do art. 198 da Constituição, dispõe sobre o aproveitamento de pessoal amparado pelo parágrafo único do art. $2^{\circ}$ da emenda constitucional n 51 , de 14 de fevereiro 2006, e dá outras providências. Diário Oficial da União, 6 Out 2006 [acesso 2013 Fev 18]. Disponível em: http://www. planalto.gov.br/ccivil_03/_ato2004-2006/2006/lei/I11350.htm

17. Brigadão JIM, Gonçalves R. Oficinas de promoção de saúde: discutindo os dilemas do cotidiano de um grupo de agentes comunitárias de saúde. Paideia. 2009;19(44):387-93.

18. Fonseca AF, Machado FRS, Bornstein VJ, Pinheiro R. Avaliação em saúde e repercussões no trabalho do agente comunitário de saúde. Texto Contexto Enferm. 2012;21(3):519-27.

19. Koda MY, Silva DV, Machado MAS, Naldos SMS. Grupo com Agentes Comunitárias: a construção de novas possibilidades do cuidar. Psicol Cienc Prof. 2012;32(2):506-15.

20. Nascimento EPL, Correa CRS. O agente comunitário de saúde: formação, inserção e práticas. Cad Saude Publica. 2008;24(6):1304-313.

21. Araújo MRN, Assunção RS. A atuação do agente comunitário de saúde na promoção da saúde e na prevenção de doenças. Rev Bras Enferm. 2004;57(1):19-25.

22. Filgueiras AS, Silva ALA. Agente Comunitário de Saúde: um novo ator no cenário da saúde do Brasil. Physis. 2011;21(3):899-916.

23. Gomes KO, Cotta RMM, Cherchiglia ML, Mitre SM, Batista RS. A práxis do agente comunitário de saúde no contexto do programa saúde da família: reflexões estratégicas. Saude Soc. 2009;18(4):744-55.

24. Ferraz L, Aerts DRGC. O cotidiano de trabalho do agente comunitário de saúde no PSF em Porto Alegre. Cienc. Saude Colet. 2005;10(2):347-55.

25. Baralhas $M$, Pereira MAO. Concepções dos agentes comunitários de saúde sobre suas práticas assistenciais. Physis. 2011;21(1):31-46.

26. Coriolano MWL, Lima LS. Grupos focais com agentes comunitários de saúde: subsídios para entendimento destes atores sociais. Rev Enferm UERJ. 2010;18(1):92-6.

27. Vasconcelos EM. Educação Popular e a atenção à saúde da família. São Paulo: Hucitec, Ministério da Saúde; 1999.

28. Fracolli LA, Almeida EZ. Teoria e prática da promoção da saúde: as concepções dos agentes comunitários de saúde. Mundo Saude. 2011;35(2):137-44.

29. Trapé CA, Soares CB. A prática educativa dos agentes comunitários de saúde à luz da categoria práxis. Rev Latino-Am Enferm. 2007;15(1):142-9.

30. Zanchetta MS, Leite LC, Perreault M, Lefebvre H. Educação, crescimento e fortalecimento profissional do Agente Comunitário de Saúde - estudo etnográfico. Online 
Braz J Nurs [Internet] [acesso 201303 18]. 2005; 4(3). Disponível em: http://www. objnursing.uff.br//index.php/nursing/article/view/35/14

31. Garcia PB. Educação Popular: algumas reflexões em torno da questão do saber. In: Brandão CR, organizador. A questão política da Educação popular. São Paulo: Brasiliense; 1980. p. 88-121.

32. Vázquez AS. Filosofia da práxis. Buenos Aires: Consejo Latinomaericano de Ciencias Sociales-CLACSO; 2007.

33. Queiros AAL, Lima LPA. A institucionalização do trabalho do agente comunitário de saúde. Trab Educ Saude. 2012;10(2):257-81.

34. Lopes $M$, Durão AV, Carvalho V. A disputa sobre os sentidos do trabalho e da formação dos Agentes Comunitários de Saúde. In: Vieira $M$, Durão AV, Lopes $M$, organizadores. Para além da comunidade: trabalho e qualificação dos Agentes Comunitários de Saúde. Rio de Janeiro: EPSJV; 2011. p. 161-208.

35. Albuquerque $\mathrm{PC}$, Stotz EN. A educação popular na atenção básica à saúde no município: em busca da integralidade. Interface (Botucatu). 2004;8(15):259-74.

36. Costa AM. Determinação social da saúde: um tema potente na mobilização pelo direito à saúde? Saude em Debate. 2009;33(83):443-6.

37. Vasconcelos E M. O significado da educação popular na realidade e na utopia da atenção primária à saúde brasileira. In: Mano MAM, Prado EV, organizadores. Vivências de educação popular na atenção primária à saúde: a realidade e a utopia. São Carlos: EdUFSCar; 2010. p. 13-8.

Bornstein VJ, Morel CM, Pereira IDF, Lopes MR. Desafíos y perspectivas de la Educación Popular en Salud para la constitución de la praxis del Agente Comunitario de Salud. Interface (Botucatu). 2014; 18 Supl 2:1327-1340.

Este estudio problematiza las practicas del Agente Comunitario de Salud en Brasil, sobretodo en relación a su trabajo como educador en el contexto de las políticas de salud y de su actuación profesional. Su construcción consideró la experiencia de las autoras en la formación técnica de ACS en la EPSJV/Fiocruz y la realización de revisión de literatura sobre el tema. Los resultados indican posibles contradicciones entre las prescripciones legales, las expectativas de los servicios en relación al trabajo del ACS y su posibilidad en constituirse como un educador popular. Por último, presenta las perspectivas y desafíos de la educación popular en salud para los cambios necesarios y posibles en la práctica de los ACS, en dirección a la efectuación de la integralidad, de la participación popular y del dialogo con el saber popular en el ámbito de la Atención Primaria.

Palabras clave: Agente Comunitario de Salud. Educación Popular en Salud. Educación en salud.

Recebido em 04/06/2013. Aprovado em 24/03/2014. 
